\title{
University Direction Case
}

\author{
by Mehtap Aldogan Eklund \\ (USA)
}

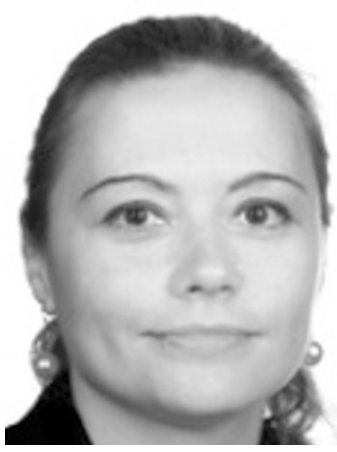

University of Wisconsin-La Crosse International Center for Corporate Governance

\section{Definition and Background}

This chapter aims to contribute to the university governance literature with a living case from Bahçeşehir University. The case is supported by the agency and stakeholder theory and the shared university governance models, such as AcademicBusiness-Corporate (ABC) of University Governance and the Integrated New University Governance (reversed KISS framework). The ABC of University Governance model is a division of resources among academic, business and corporate boards (Carnegie \& Tuck, 2010). The framework of reversed KISS stands for 'Situational, Strategic, Integrated, Keep it Controlled' (Hilb, 2012). The shared or integrated governance concept was developed based on stakeholder theory, which shifts the panoptic (shareholder) view to a panoramic (stakeholder) vision (Pesqueux \& Damak-Ayadi, 2005). This chapter helps the governing bodies and management authorities in tertiary education gain a deeper understanding of the governance models and evaluate their existing governance structure in the higher education institutions (HEIs).

\section{Information on Bahçeşehir University}

Bahçeşehir University (BAU) consists of Bahçeşehir University in Istanbul, Turkey (BAU Istanbul) and Bahçeşehir International Universities (BAU Global), such as one in the USA (Washington D.C.), Germany (Berlin), Georgia (Batumi) and the 
Northern Cyprus (Nicosia) (BAU, 2017a, 2017e). These four private universities abroad, collected under BAU Global umbrella, are independent; they have their own rectors, yet they have one shared board of trustees (BAU, 2017c). However, in this book chapter, the university governance structure of BAU Istanbul is analysed in detail.

In 1998, BAU Istanbul was established as a foundation university (FU) by the Bahçeşehir-Ugur Education Foundation. The founding chairman of BAU, Mr. Enver Yücel, is a successful education entrepreneur (edupreneur). BAU Istanbul consists of nine faculties, three graduate schools, one school of languages and two vocational schools. It has 3 campuses, 22,446 students and 1047 faculty members. The university provides more than 100 programs. It aims to be ranked among the top 500 universities in the world by the year 2023. The governing bodies of the university are very good to respond the needs of the twenty-first century, such as digitalization, innovation, entrepreneurship, virtual education, machine learning, cybersecurity, data mining and big data (Ince, 2016; Yalçin, 2017). For the entrepreneurship, BAU in Turkey has the incubation centre in Istanbul, and BAU Global has the centre in the Silicon Valley, USA (BAU, 2018b, 2018c). These centres guide their students to be an entrepreneur and start-up their own companies.

\section{The University Governance Structure of the Bahçeşehir University in Istanbul (BAU Istanbul)}

Brown (2001, p. 91) expressed that 'the successful universities do have a very successful and strong governance structure'. In this section, BAU Istanbul's unitary governance structure is analysed according to the ABC of University Governance and the holistic and integrated reversed KISS framework (New University Governance). These two concepts are explained and implemented in the living case.

As shown in Fig. 1, ${ }^{1}$ the governance organs of BAU Istanbul encompass the following bodies: (1) board of trustees (BOT), (2) rector's office (rectorate), (3) board of directors (BOD) and (4) Senate.

The board of trustees (BOT) is the highest decision-making authority; it represents its legal entity and includes a minimum of seven members. The main duties of the BOT are to direct and control the university, appoint the rector after obtaining the affirmative opinion of the Higher Education Council (YÖK), approve the university budget and monitor its implementation and to make the final decision regarding the resolution of conflicts between various bodies of the university. As of 2018, the seven members of BOT are made up of two internal members (founding chairman and the rector) and five external members with diverse backgrounds. The chairman is elected among the members of the BOT. Each member is appointed for

\footnotetext{
${ }^{1}$ The figure was derived from Hilb, M. (2012). Integrierte Governance von Universitäten: Haupt, p.36 and implemented to the case. In the unitary board system, rector is also the members of university board and Senate, which is opposite to dual board system.
} 
Fig. 1 BAU Istanbul's unitary governance structure

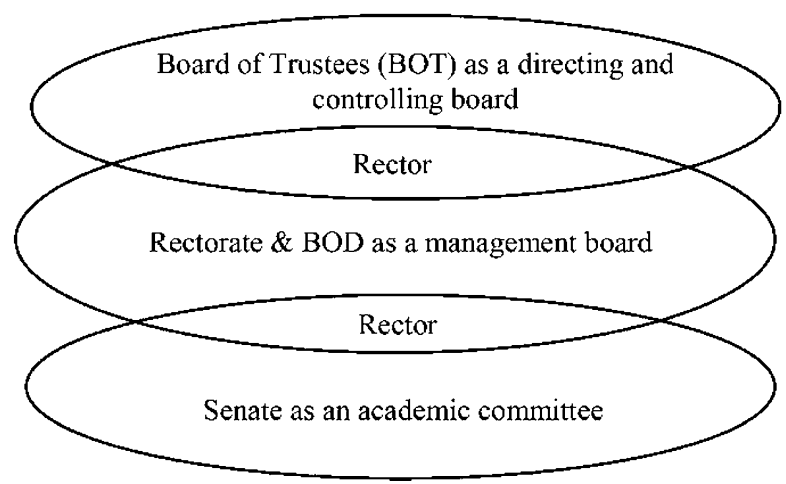

4 years, and they can be reappointed by the chairman. The BOT has to be gathered biannually, and the majority of the members must have a bachelor's degree (BAU, 2018a).

Rectorate (rector's office) is the executive or the management board of the university, and rector is the president of it. The BOT appoints the rector by a plurality of the vote for 4 years. He can be nominated again after completing the period of duty. The rectorate consists of six people (rector, vice-rectors and advisors to rector). The rector and vice-rectors must be a full professor, but the advisors do not necessarily have to be academic. Instead, for instance, the rector's advisor in charge of marketing and communication is a professional who has an expertise in journalism, media and communication. The board of directors (BOD) is the authority to assist the rectorate for the executive and administrative matters. The BOD has 13 members with voting rights: the rector, who is also the president of the BOD, the deans of 9 faculties and 3 elected full-time professors at BAU (BAU, 2017b, 2017d; Yalçin, 2017).

The Senate is the academic organ of the university, and it gathers at least biannually - the beginning and end of the academic year. It is the organ in charge of the academic decisions and their implementations (BAU, 2017b; Yalçin, 2017). The Senate consists of 27 members with voting rights (rector, vice-rectors, deans of 9 faculties, elected academics, leaders of the institutes, vocational schools and school of languages) and 2 members as an observer, no voting rights (the president of the student council and secretary-general) (BAU, 2018a).

In short, BOD and Senate include only academics working in the university. In line with the unitary (monistic) governance structure, as seen in Fig. 1, the rector is the president of three committees - rectorate, BOD and Senate-and the member of the BOT. The rector acts as a mediator among academic, business and corporate boards. Consistent with the agency cost and information asymmetry assumptions of the agency theory (Eisenhardt, 1989), the unitary governance structure of the BAU Istanbul is advantageous for the stakeholders because the rector can bring university related know-how and information to the BOT, so it decreases the information asymmetry and agency cost. To cope with the disadvantages of unitary board structure, BAU Istanbul has addressed check and balances and conflict of interest 


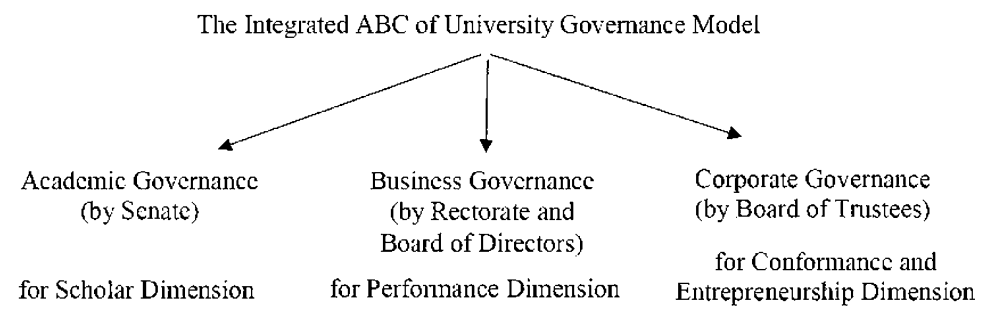

Fig. 2 The BAU Istanbul's the ABC (Academic-Business-Corporate) of University Governance structure

by not allowing the rector to be the chairman of the BOT and by not involving the rector in BOT's meeting when they discuss the issues related to the rector. As a result, it can be concluded that BAU Istanbul's unitary governance structure is successfully implemented and managed.

From the perspective of the ABC of University Governance model, BAU Istanbul has three organs which fulfil the academic governance, business governance and corporate governance as seen in Fig. 2. ${ }^{2}$ In other words, BAU Istanbul has integrated/shared or amalgam model which considers the whole stakeholder's interests. Furthermore, the BOT is an entrepreneurial board where various entrepreneurial and innovative decisions are taken and where the incubator centres and the programmes addressing the needs of the twenty-first century are initiated. Therefore, the BOT is a great example of 'corporate university control-preneurship', which was defined as 'controlling, directing, and entrepreneurial board' by Hilb (2009).

From the aspect of New University Governance, Hilb (2005, 2006, 2012) proposed reversed KISS framework articulated into four parts:

Keep It Situational (S) It indicates context dimension that depends on institutional theory. There is no 'one-fits-all' approach available. University governance structure should be modified by considering internal and external contexts (Hilb, 2012). For instance, the governance structures in the examples below should not be the same:

Public University $\neq$ Foundation University $\neq$ Private University

Big Scale University $\neq$ Small-Scale University

Local University $\neq$ Global University

BAU has differentiated its governance structure by considering the external and internal contexts. For example, its university governance structure is different from the ones at public universities and local universities. BAU Istanbul is way bigger in size than the size of BAU Global universities abroad, and the ambition level of the

\footnotetext{
${ }^{2}$ Prepared by the author by deriving the concepts from Carnegie, G. D. and Tuck, J. (2010) 'Understanding the ABC of University Governance', Australian Journal of Public Administration, 69(4), pp. 431-441, and Hilb, M. (2012). Integrierte Governance von Universitäten: Haupt, p.15
} 
BOT at BAU Istanbul is higher than the one at BAU Global. BAU Istanbul is a foundation university; BAU Global consists of private international universities. Therefore, BAU has kept its university governance situational (-S) by having two different BOTs for BAU Istanbul and BAU Global, in other words, BOT of BAU Istanbul $\neq$ BOT of BAU Global.

Keep It Strategic (S) It is for strategic direction based on stakeholder theory. The strategic development is a central function of the board, and the board should include competent and exemplary members who act as a role model for both share- and stakeholders (Hilb, 2005, 2006). In our case, the BOT of BAU Istanbul does not act only as a supervisory board, but it also directs, controls and takes strategic decisions. Moreover, the founding chairman selects the members based on their competence. As of 2018, the BOT of BAU Istanbul includes five external members in addition to two internal members (rector and chairman). Mr. Enver Yücel, the founding chairman, and his son (Mr. Ömer Yücel), who will be the prospective chairman, are currently the member of the BOT (Yalçin, 2017). The members have a diverse background, such as politician and professionals from finance.

Keep It Integrated (I) It is related to board management that is derived from resource dependence theory. It means the integrated and targeted selection, appraisal, compensation and development of the board (supervisory board) and the rectorate (managing board) (Hilb, 2012). Consistent with the unitary board structure, at BAU Istanbul, the rector is sitting both in the BOT (supervisory board) as a member and in the rectorate (managing board) as a president, which helps the integration, evaluation, appraisal and compensation processes of the personnel. On the other hand, the rector is not allowed to attend the BOT meeting when they take the decisions about his assessment and compensation. The founding chairman evaluates and assesses the members of the BOT, and their reappointment is depending on their appraisal and evaluation.

Keep It Controlled (K) It is about the strategic control direction built upon agency theory. This dimension is regarding the monitoring and risk management functions of the board. It indicates holistic monitoring of the results from the perspective of stakeholders including shareholders, government, students, alumni, academics, researchers, staff, corporate partners/professionals and the public (Hilb, 2011, 2012). The BOT of BAU Istanbul does also act as a risk committee and takes strategic decisions in the high-risk environment. Risk management is a very important role of BOTs for the global FUs operating in the emerging markets. For instance, although Turkey has experienced unstable economic conditions in the passing years, the BOT of BAU Istanbul has coped with the external risk factors very well due to its successful risk management strategies, so the financial bottom line, education quality and the number of international and national students have not been negatively affected (Yalçin, 2017). For the holistic monitoring, most of the stakeholders are represented in the government bodies of BAU Istanbul. For instance, the appointed practitioners and politician and elected academics and student representative are 
involved in the university governance of BAU Istanbul. They aim to bring the expectations of the stakeholders into the Senate or boards to be discussed and fulfilled.

\section{$4 \quad$ Questions}

- What are the main strengths of the university direction in this case?

- What do you recommend as areas of development in this case?

\section{Discussion and Conclusion}

The unitary governance structure of BAU Istanbul is a good example of the $\mathrm{ABC}$ of University Governance and the reversed KISS framework (New University Governance model), and it was built upon amalgam governance approaches. Amalgam governance means integrated or shared governance, which includes all of the following governance forms in Fig. $3:^{3}$

On the other hand, for the areas of development in this case, first, the role of the $\mathrm{BOD}$ at BAU Istanbul is assisting the rector in the administration and management decisions and duties (BAU, 2018a). It sounds similar to the management board. The BOD shall be renamed as management board. Second, in addition to the existing members in the BOT of BAU Istanbul, one or two more independent/external members who excel in financial management in the private institutions and corporations shall be appointed to the BOT, so it may help the university to be managed as a university business and increase its income (the financial bottom line) even though making profit is not the main driver of the foundation universities. As Rowlands (2014, p. 273) stated, 'Being an academic leader and doing university

\begin{tabular}{|ll|}
\hline Faculty Governance & $\rightarrow$ through Senate \\
\hline Managerial Governance & $\rightarrow$ through Rectorate and Board of Directors (BOD) \\
\hline Governmental Governance & $\rightarrow$ through Higher Education Council (YÖK) \\
\hline Business Governance & $\rightarrow$ through business representatives (practitioners) at BOT \\
\hline Independent Governance & $\rightarrow$ through external members at BOT \\
\hline Trustee Governance & $\rightarrow$ through the Board of Trustees (BOT) \\
\hline $\begin{array}{l}\text { Stakeholder Governance } \\
\text { student council president, politician, professionals in the governance organs of BAU Istanbul }\end{array}$ \\
\hline
\end{tabular}

Fig. 3 Amalgam governance of BAU Istanbul

\footnotetext{
${ }^{3}$ The figure was derived from Hilb, M. (2012). Integrierte Governance von Universitäten: Haupt, p.31 and implemented to the case.
} 
leadership are not the same thing (academic leader versus executive leader)'. The contemporary business university governance has more generally shifted to managerialism. 'In the managerialism, the focus is on professional management, performance, management by results, value for money and closeness to the customer or market' (Rowlands, 2014, p. 265). It is believed that the involvement of independent business experts in BOTs shall provide universities with long-term success and benefits. Third, most stakeholders are already involved in the government organs of the BAU Istanbul. For instance, student council president is the observant in the Senate, yet he/she does not have a voting right. It is important that all stakeholders be equally represented in the government organs of universities according to the stakeholder theory. Therefore, it shall be a good idea to appoint the student council representative as a member with voting right in the Senate. Fourth, alumni and public, such as the family members of the students or any interested parties in the education of the university, are not represented in the government organs of the university. For instance, INSEAD Business School and London Business School have an advisory board (Alumni Board or International Council) that includes alumni from various countries and board members or CEOs of international companies. The main objective of the advisory board is to offer innovative advice and dynamic perspectives to fulfil the expectations of the stakeholders. They gather either quarterly or biannually (Hilb, 2012). It is suggested implementing the same concept into BAU Istanbul by setting up an advisory board that is independent of other governing bodies of the university. Fifth, as Hilb (2012) mentioned in his New University Governance model, for the bigger universities, integrated HR committee is suggested to be established to involve in the nomination, evaluation, appraisal and compensation functions of BOT and rectorate. It may also be a good idea for BAU Istanbul to establish HR committee. On behalf of transparency, the assessment and evaluation procedures of the BOT shall be described in the by-laws of the university. Last of all, the CVs or the brief information of each board of trustees should be available to the public on the web page of BAU to increase the transparency and to highlight the level of diversity and independence.

\section{What We Have Learned from This Case}

1. We have learned the holistic (network or integrated) and New University Governance concepts in the twenty-first century: the ABC of University Governance and New University Governance (integrated reversed KISS) frameworks, which are opposite to traditional top-down approach, e.g. a German chair-based organization system.

2. BAU Istanbul's unitary governance structure is a good example of the ABC of University Governance and New University Governance models. Its long-term academic and financial success mainly depends on the stakeholder (shared governance) approach and the fulfilment of the needs of stakeholders. It proves that 'the successful universities have a very successful and strong governance structure' (Brown, 2001, p. 91). BAU Istanbul's governance structure would be a 
good benchmark for the foundation universities which are comparable in the external and internal contexts (keep it situational).

3. There is no such thing as 'one-size-fits-all' model of governance. The governance problems may be comparable in different tertiary institutions. The need is to avoid replicating bad practice while trying to benchmark good practice. Good university governance also does not simply happen. It requires boards of governors to recognize when a governance model is not working and to question why it is not working and how to repair it (Trakman, 2008).

4. The art of being a successful chairperson is to have his/her nose in but her/his hands out (Hilb, 2012).

5. The management in HEIs may refer to the insights and suggested governance models in the book chapter to analyse or improve their university governance structure.

Acknowledgement The author is grateful to Enver Yücel (chairman), Prof. Dr. Şenay Yalçin (rector) and Assist. Prof. Dr. Sibel Baykut (advisor to the rector) at Bahçeşehir University for sharing the valuable information and attending the interview for this book chapter.

\section{References}

BAU. (2017a). Bahcesehir University with numbers. http://www.bahcesehir.edu.tr/icerik/2511bahcesehir-university-in-numbers

BAU (2017b). BAU by-laws and the definition of the roles in the University governance.

BAU. (2017c). BAU Global. http://bahcesehir.edu.tr/icerik/3487-bahcesehir-university

BAU. (2017d). The management of the BAU. http://www.bahcesehir.edu.tr/kadro/board_trustees

BAU. (2017e). The vision and the mission. http://www.bahcesehir.edu.tr/icerik/4236-mission-andvision.

BAU (2018a) Bahcesehir Universitesi Ana Yonetmeligi/Bahcesehir University By-laws.

BAU. (2018b). BAU Global Silicon Valley Incubation Center. https://bauglobal.com/academiccenter/bau-silicon-valley/

BAU. (2018c). BAU TTO, Incubation Center. http://tto.bahcesehir.edu.tr/en/student/incubaitoncenter/ (in English); or http://tto.bahcesehir.edu.tr/ogrenci/kulucka-merkezi/ (in Turkish).

Brown, W. (2001). Faculty participation in university governance and the effects on university performance. Journal of Economic Behavior \& Organization, 44, 129-143.

Carnegie, G. D., \& Tuck, J. (2010). Understanding the ABC of university governance. Australian Journal of Public Administration, 69(4), 431-441.

Eisenhardt, K. M. (1989). Agency theory: An assessment and review. The Academy of Management Review, 14(1), 57-74.

Hilb, M. (2005). New corporate governance: From good guidelines to great practice. Corporate Governance: An International Review, 13(5), 569-581.

Hilb, M. (2006). New corporate governance: Successful board management tools (1st ed.). Switzerland: Springer.

Hilb, M. (2009). Glocal management of human resources (2nd ed.). LIT.

Hilb, M. (2011). New corporate governance: Successful board management tools (4th ed.). Switzerland: Springer.

Hilb, M. (2012). Integrierte Governance von Universitäten. Haupt.

Ince, C. (2016). The facts of BAU University and BAU Global. https://www.youtube.com/watch? $\mathrm{v}=\mathrm{t} 6 \mathrm{cCUzqs} 1 \mathrm{Lc}$ 
Pesqueux, Y., \& Damak-Ayadi, S. (2005). Stakeholder theory in perspective. Corporate Governance: The International Journal of Business in Society, 5(2), 5-21.

Rowlands, J. (2014). Present but not counted: The tenuous position of academic board chairs within contemporary university governance. International Journal of Leadership in Education, 18(3), 263-278.

Trakman, L. (2008). Modelling university governance. Higher Education Quarterly, 62(1/2), 63-83.

Yalçin, Ş. (2017). The information of BAU and its university governance. Istanbul: Interviewer: M. A. Eklund.

Open Access This chapter is licensed under the terms of the Creative Commons Attribution 4.0 International License (http://creativecommons.org/licenses/by/4.0/), which permits use, sharing, adaptation, distribution and reproduction in any medium or format, as long as you give appropriate credit to the original author(s) and the source, provide a link to the Creative Commons licence and indicate if changes were made.

The images or other third party material in this chapter are included in the chapter's Creative Commons licence, unless indicated otherwise in a credit line to the material. If material is not included in the chapter's Creative Commons licence and your intended use is not permitted by statutory regulation or exceeds the permitted use, you will need to obtain permission directly from the copyright holder.

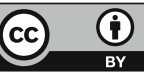

